\title{
Diensthabende
}

\section{Der innere Wert}

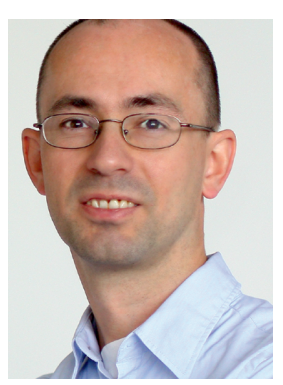

Sie ist die unangenehmste „Nebenwirkung“ des Medizinstudiums. Und manche leiden so sehr unter ihr, dass sie ihnen die Lebensfreude vergällt: Prüfungsangst. In diesem Heft erzählen vier junge Mediziner, wie sie diese spezielle Form des Lampenfiebers bekämpfen (S. 26): Manche versuchen es mit Selbsthypnose oder Klangschalen, andere machen die Nacht vor der Prüfung durch, um mittels Übernächtigung die Angststarre zu lösen. Doch so hilfreich solche Tipps im Einzelfall sein mögen, viele Studenten leiden trotzdem vor ihrem Examen, als stünde der Sensenmann persönlich vor der Tür. Woher kommt diese komplett unverhältnismäßige Angst? Psychologen sehen die Wurzel des Problems darin, dass viele das Bestehen einer Prüfung zu einer Art Schicksalsfrage machen im Sinne von: Bin ich etwas wert? Wird mein Leben erfolgreich sein? So baut man einen inneren Druck auf, der einen fast explodieren lässt. Dabei ist der Ausweg (eigentlich) ganz einfach. Wer Versagensängste in sich aufwallen fühlt, sollte sich folgende Frage stellen: Fällt dieses Examen tatsächlich ein Urteil darüber, ob ich nun ein schlechter oder ein guter Mensch bin? Natürlich nicht! Erfolg in Studium und Beruf ist nur äußere Lackierung. Was wir wirklich wert sind, steckt so tief in uns drin, dass eine Multiple-Choice-Prüfung das niemals herausfinden wird.

Herzlichst, euer Dieter Schmid

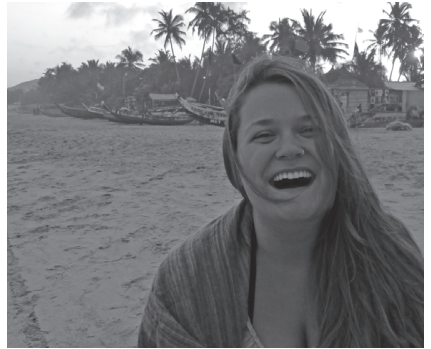

Laura Olbrich

arbeitet seit Anfang des Jahres in der Kinderklinik der Uni Düsseldorf. Ihre Leidenschaft gilt dem Thema Globale Gesundheit. Deswegen hat sie den größten Teil ihres Praktischen Jahres in Afrika verbracht. In diesem Heft berichtet sie von ihrem PJ-Tertial am „Red Cross“ in Kapstadt (S. 14).

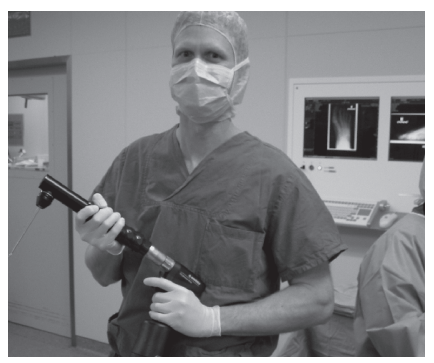

Dr. Andreas Ellinger

absolvierte seine Weiterbildung auf der Viszeralchirurgie und entschloss sich dann, den Frakturen den Kampf anzusagen - wo erforderlich auch mit schwerem Gerät. Auf Seite 36 präsentiert er uns das „Arsenal“ der unfallchirurgischen Instrumente.

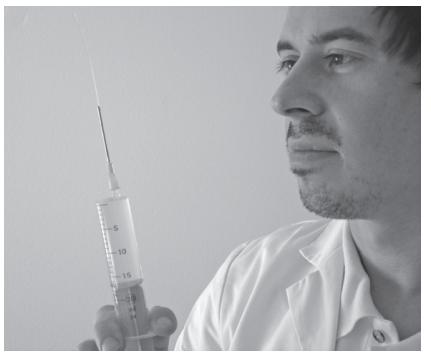

Dr. Mikolaj Walensi

hat seine ersten Erfahrungen mit Injektionen und Spritzen schon als Zivi gesammelt. Mittlerweile ist er angehender Gefäßchirurg. In seinem Artikel zur subkutanen und intramuskulären Injektion (S. 40) erklärt er, worauf man achten muss, wenn man Medikamente per Nadel appliziert. 